\title{
Literacia Pré-Escolar e Desempenho na Leitura na Instrução Primária
}

Patrícia Pinto ${ }^{1}$

Câmara Municipal de Matosinhos

João A. Lopes

Escola de Psicologia da Universidade do Minho

\begin{abstract}
RESUMO - A literacia pré-escolar tem recebido uma crescente atenção. Neste estudo, participaram 70 crianças que iniciaram o $1 .^{\circ}$ ano de escolaridade no ano letivo 2009/10 e que, na educação pré-escolar, frequentaram três instituições com abordagens diferenciadas de leitura e de escrita. $\mathrm{O}$ estudo inclui quatro medidas repetidas no tempo nas áreas da fonologia, reconhecimento de letras, palavras e velocidade de leitura. Os resultados sugerem que a abordagem específica à leitura na educação pré-escolar condiciona o desempenho da leitura na instrução primária. Contudo, essa influência parece ser atenuada com o tempo. Por outro lado, verificou-se que sujeitos que receberam instrução direta de leitura em idade pré-escolar (mas não treino fonológico) obtêm resultados significativamente superiores em tarefas fonológicas aos de sujeitos que receberam treino fonológico prolongado (mas não de leitura).
\end{abstract}

Palavras-chave: literacia emergente, leitura, consciência fonológica, velocidade de leitura

\section{Preschool Literacy and Reading Performance in Primary School}

\begin{abstract}
The debate regarding kindergarten literacy has received increasing attention and social visibility. In this study, participants are 70 children who attended first grade in 2009/2010. Participants attended three kindergartens with unique approaches to reading. A four wave repeated measure design was conducted to investigate the growth of the children in phonological awareness, letter recognition, word recognition, and reading speed. Results suggest that the approach towards reading and writing in kindergarten affects children's performance in grades 1 and 2 of elementary school. This influence, however, seems to fade over time. Moreover, results show that children who received formal reading instruction in kindergarten, perform significantly better in phonological tasks than children who received direct and extended phonological instruction.
\end{abstract}

Keywords: emergent literacy, reading performance, phonological awareness, reading speed

O estudo do modo como se processa a aprendizagem da leitura e das competências facilitadoras dessa aprendizagem tem despertado o interesse de muitos investigadores (e.g., Castro \& Gomes, 2000; Spear-Swerling \& Sternberg, 1996). A investigação tem evidenciado que o modo como as crianças iniciam a aprendizagem formal da leitura condiciona o seu percurso escolar, mas é igualmente influenciado pelas experiências e oportunidades proporcionadas antes da alfabetização. Por exemplo, crianças em idade pré-escolar, especialmente as provenientes de contextos em que os pais têm elevados níveis de literacia e em que há muita exposição a material impresso, possuem em geral um significativo conhecimento de conceitos relacionados com a leitura e com a relação entre oralidade e escrita, antes de iniciarem a aprendizagem formal (Cadime et al., 2009; Lopes, 2010; Martins \& Niza, 1998).

A evolução na aquisição da leitura não ocorre de forma natural e automática pela simples exposição a livros e material impresso, ou seja, na ausência de instrução formal. Embora as experiências que antecedem a escolarização sejam relevantes para o percurso escolar dos alunos, a aprendizagem da leitura normalmente requer a interação com um adulto que

1 Endereço para correspondência: Escola de Psicologia da Universidade do Minho, Campus de Gualtar, Braga, Portugal. CEP. 4710-057. E-mail: patpinto_80@hotmail.com sistematicamente dirija a atenção da criança para as letras e para o código alfabético. O desenvolvimento da consciência fonológica é, nesse caso particular, paradigmático. De modo geral, os estudos (e. g., Lima, 2009; Sim-Sim, 1998; Yopp \& Stapleton, 2008) têm evidenciado que as crianças têm uma sensibilidade implícita a unidades fonêmicas das palavras e sílabas, e mesmo crianças muito pequenas já são capazes de manipular conscientemente as sequências de fonemas entre os 3 e os 4 anos de idade. Isso não significa, no entanto, que as crianças consigam aplicar essas competências à logica do sistema alfabético (McGuinness, 2005).

Os resultados da investigação mostram ainda que a consciência fonológica apresenta uma evolução significativa como resultado da instrução em um sistema alfabético de escrita (Martins \& Farinha, 2006; McGuinness, 2005). A sua capacidade preditiva no sucesso da aprendizagem da leitura é, por isso, questionada por muitos autores. É importante notar que os estudos que evidenciam que as crianças que apresentam um bom processamento fonológico no final da educação pré-escolar apresentam igualmente sucesso na aprendizagem da leitura (e. g. Cadime et al., 2009; Fernandes, 2005; Martins \& Silva, 2006; McGuinness, 2005; Silva, 2003; Yopp \& Stapleton, 2008) não se referem à consciência fonêmica mas ao conceito mais amplo de processamento fonológico. Assim, enquanto é plausível a existência de 
determinado tipo de conhecimento fonológico como aquele que está implícito na percepção da rima, não parece possível a existência de um conhecimento fonêmico fora do contexto da relação entre as letras e os sons, presente nos sistemas alfabéticos (Lopes, 2010; MacGuiness, 2005).

Da revisão da literatura, tem resultado a pergunta acerca de "quando se deve começar" a aprendizagem da leitura e da escrita, considerando-se que esta deve acontecer cedo, ainda que não seja possível fixar um momento específico (Cruz, 2011). A literatura sugere (e.g., Koutsoftas, Harmon, \& Gray, 2009; Lopes \& Fernandes, 2009) que, no jardim-deinfância, é possível promover conhecimentos e competências no domínio da linguagem oral e escrita, para que o início formal da aprendizagem da leitura e da escrita tenha maior probabilidade de ocorrer sem problemas.

Do ponto de vista curricular e programático, a abordagem à leitura e à escrita na educação pré-escolar tem sido operacionalizada sob a forma de competências. Essas competências são distintas conforme as perspetivas adotadas, sendo, por outro lado, significativas as variações entre países. Em Portugal, por exemplo, embora existam orientações curriculares e, recentemente, metas de aprendizagem que definam como relevante a abordagem à linguagem oral $\mathrm{e}$ à linguagem escrita no jardim-de-infância, há limitações que condicionam as práticas pedagógicas e que decorrem da formação dos educadores e projetos educativos das instituições (Ministério da Educação, 1997, Fernandes, 2005; Sim-Sim, 2001). A abordagem à leitura e à escrita parece, por isso, desenvolver-se em um continuum que varia entre a não-abordagem desse domínio e o ensino formal da leitura e escrita, praticada em algumas escolas. A promoção de práticas de literacia emergente (promoção informal da literacia) pode ser considerada uma perspetiva intermediária, em que são privilegiadas a linguagem oral e a linguagem escrita.

Os Jardins-Escola João de Deus ${ }^{1}$ constituem um exemplo paradigmático do ensino formal da leitura e da escrita a crianças em idade pré-escolar. Nessas instituições, os educadores utilizam a chamada Cartilha Maternal e as crianças vão aprendendo regras, evoluindo e construindo conhecimento sobre a leitura e a escrita desde a educação pré-escolar. $\mathrm{O}$ acesso à leitura é direto, sem retificações intermediárias e sem sobrecarregar a memória com um número excessivo de associações básicas (Ruivo, 2006).

Nas últimas décadas, têm sido desenvolvidos diversos estudos no sentido de perceber a influência das práticas de jardim-de-infância na aprendizagem formal da leitura e da escrita. Kendeou, Broek, White e Lynch (2009) procuraram verificar em que medida as competências de linguagem oral e de decodificação avaliadas na educação pré-escolar prediziam o desempenho na compreensão leitora no $1 .^{\circ}$ ciclo, tendo concluído que o sucesso na compreensão leitora depende das competências de descodificação, designadamente da consciência fonológica e da identificação de letras e palavras, mas também de competências de linguagem oral, como o vocabulário e a compreensão oral. Aliás, esse estudo mostrou

1 Poeta e pedagogo português do século XIX. Publicou em 1876 a célebre Cartilha Maternal, método de ensino da leitura verdadeiramente revolucionário no panorama pedagógico português e que ainda hoje é utilizado nos Jardins-Escola João de Deus. que as competências de linguagem oral explicam uma maior percentagem da variância dos resultados na compreensão leitora do que as competências de descodificação.

No sentido de analisar a influência da abordagem à leitura e escrita realizada na educação pré-escolar no desempenho no $1 .^{\circ}$ ciclo, Vellutino e Scanlon (1987) acompanharam um grupo de crianças desde o jardim-de-infância até ao final do $1 .^{\circ}$ ano de escolaridade. Quando as crianças se encontravam no $1 .^{\circ}$ ano de escolaridade, foram agrupadas em três grupos de acordo com o desempenho na leitura (pobres, médios e bons leitores). Os resultados sugerem que os bons leitores provêm de salas de educação pré-escolar em que se dedica mais tempo a atividades de consciência fonológica, escrita e soletração. Os outros dois grupos não diferiam em termos dessas caraterísticas. Os autores verificaram ainda que são determinantes para o sucesso na aprendizagem da leitura e da escrita no $1 .^{\circ}$ ano de escolaridade as competências cognitivas dos alunos, mas também o tipo de instrução recebida na educação pré-escolar. Constatou-se, no entanto, que as variáveis instruccionais distinguiam mais frequentemente os bons leitores dos restantes, enquanto as variáveis cognitivas distinguiam os maus leitores dos restantes.

Apesar da literatura publicada, praticamente não há estudos que comparem o desempenho em idade escolar de grupos de crianças provindas de jardins-de-infância com práticas diferenciadas de literacia. Para além do interesse teórico, essa é uma questão com interesse prático, já que muitos educadores se interrogam se vale a pena antecipar aquisições usualmente realizadas no início da escolaridade formal e muitos pais pretendem antecipar a entrada dos filhos na escola, mesmo que estes não tenham formalmente idade para tal, para que "não percam tempo". Tendo em conta essas dúvidas e interrogações, desenhamos um estudo cujo objetivo central é perceber se crianças provenientes de três jardinsde-infância com modelos educativos específicos (no que à iniciação à leitura diz respeito), apresentam desempenhos diferenciados no que tange ao processamento fonológico, ao reconhecimento de letras, ao reconhecimento de palavras e à velocidade leitora, ao longo do $1^{\circ} \mathrm{e}$ do $2^{\circ}$ ano de escolaridade.

\section{Método}

\section{Participantes}

Participaram no estudo 70 crianças que iniciaram em 2009/2010 o $1 .^{\circ}$ ano de escolaridade. Na educação pré-escolar, essas crianças frequentaram três instituições diferentes:

- Jardim-Escola João de Deus, instituição em que as crianças, no último ano da educação pré-escolar, aprendem formalmente a leitura e a escrita. No JardimEscola João de Deus, a educadora implementava sistematicamente um conjunto de atividades direcionadas para o ensino formal da leitura e da escrita que incluía diariamente: hora do conto, realização de atividades de promoção da consciência fonológica, instrução direta das letras, iniciação à leitura com a Cartilha Maternal e escrita de palavras e de frases. $\mathrm{O}$ acesso à leitura é direto 
e tem início com a visualização das letras por parte da criança, seguindo-se os sons correspondentes, a leitura de palavras e a sua pronunciação enquanto entidades globais com significado próprio.

- Uma Instituição Privada de Solidariedade Social (IPSS) do Concelho de Matosinhos, Portugal, onde é aplicado de forma sistemática, em uma base anual, um programa de promoção da literacia emergente no âmbito do projeto A Ler Vamos..., direcionado para a promoção de competências de literacia emergente. Centra-se na intervenção com crianças de quatro e cinco anos e respetivos pais e educadores. O projeto contempla uma avaliação individual e uma intervenção semanal com as crianças em risco de apresentarem dificuldades na aprendizagem inicial da leitura e da escrita, a formação de educadores nesse domínio, bem como reuniões trimestrais com os pais. É valorizada a promoção de competências de linguagem oral (vocabulário, conhecimento morfossintáctico), de linguagem escrita (aspetos figurativos e conceptuais e convenções da escrita) e de competências metalinguísticas. Atualmente o projeto abrange a rede pública e todas as IPSSs do concelho.

O projeto A Ler Vamos... inclui um programa estruturado destinado a crianças em idade pré-escolar. Os objetivos, número de sessões, materiais e sequência de implementação são pré-definidos. A implementação requer a presença de um psicólogo, que é responsável pelo planejamento, execução e avaliação da intervenção. Em cada sessão, é efetuada uma ativação de conhecimentos prévios das crianças e a leitura de uma história. Concluída a leitura, são efetuadas atividades no âmbito da literacia emergente relacionadas com a história. Às educadoras, é apresentado o racional teórico do programa e as opções tomadas na sua elaboração e é ainda sugerido que implementem na sala as atividades propostas, com uma frequência semanal. Nesse sentido, e através da colaboração com o projeto, a educadora da IPSS do concelho de Matosinhos, apresentava uma rotina diária de exploração de livros e de histórias, realização de jogos com sons (tarefas de segmentação, classificação e manipulação silábica e fonêmica) e escrita livre e monitorizada pela educadora.

- Uma IPSS do Concelho de Caminha, Portugal, que não desenvolve atividades específicas orientadas para a promoção da leitura e da escrita.

As duas primeiras instituições apresentam caraterísticas urbanas. A última, caraterísticas semiurbanas.

\section{Instrumentos}

Bateria de Provas de Consciência Fonológica (Silva, 2002). Essa prova avalia as competências fonológicas no jardim-de-infância e inclui seis subtestes. O subteste 1 classificação com base na sílaba inicial - apresenta 14 itens e avalia a capacidade infantil para detectar sílabas iniciais idênticas em diferentes palavras. O subteste 2 - classificação com base no fonema inicial -, com 14 itens, avalia a capacidade para detectar fonemas iniciais idênticos em diferentes palavras. Nesses dois subtestes são apresentadas quatro imagens. A criança deve selecionar as duas que começam pela mesma sílaba ou pelo mesmo fonema. Os subtestes 3 - supressão da sílaba inicial (14 itens) - e 4 - supressão do fonema inicial (24 itens) - constituem tarefas de manipulação e implicam a eliminação de uma sílaba ou de um fonema de uma palavra apresentada oralmente. Nesses dois subtestes, é solicitado que a criança pronuncie o "que fica" de uma palavra, quando lhe é retirada a sílaba ou fonema inicial. O subteste 5 - análise silábica - e o subteste 6 - análise fonêmica - requerem que a criança identifique as sílabas e os fonemas de palavras apresentadas oralmente. Ambos os subtestes são constituídos por 14 itens. Neste estudo, foram utilizados os subtestes de classificação e de manipulação das sílabas e dos fonemas (subtestes 1, 2, 3 e 4).

Prova de Reconhecimento de Letras (Silva, 2003). Para avaliar o reconhecimento de letras, foi utilizada a prova do nome de letras de Silva (2003). Nessa prova, são apresentadas à criança as letras maiúsculas do alfabeto (com as quais as crianças dessa faixa etária estão mais familiarizadas, excluindo W, K e Y). A apresentação das letras é efetuada em formato digital, em uma apresentação em power point. As instruções fornecidas às crianças incluíam a indicação de que as letras surgem na tela sucessivamente, depois de se clicar no lado direito do mouse. A passagem dos slides podia ser efetuada pela criança ou pelo avaliador.

Prova de reconhecimento de palavras (PRP; Viana \& Ribeiro, 2006). A PRP é uma prova de reconhecimento de palavras regulares, destinada a avaliar a velocidade e a precisão de leitura. É uma prova unidimensional constituída por 40 itens (mais três de treino). Cada item é constituído por uma imagem, seguida de quatro palavras. Dessas palavras, 20 são de duas sílabas e 20 são de três sílabas). Os valores de consistência interna para os diferentes anos de escolaridade $\left(1^{\circ}, 2^{\circ}, 3^{\circ}\right.$ e $\left.4^{\circ}\right)$ variam entre 0,95 e 0,84 , na aplicação sem limite de tempo, e entre 0,96 e 0,98 na aplicação com limite de tempo.

Tabela 1. Caracterização dos participantes

\begin{tabular}{lcccccccc}
\hline & \multicolumn{1}{c}{ Masculino } & \multicolumn{1}{c}{ Feminino } & \multicolumn{5}{c}{ Idade } \\
\hline & $\boldsymbol{N}$ & $\boldsymbol{\%}$ & $\boldsymbol{N}$ & $\boldsymbol{\%}$ & $\boldsymbol{M}$ & $\boldsymbol{D P}$ & Min. & Máx. \\
Jardim-escola João de Deus & 13 & 44,8 & 16 & 55,2 & 6,45 & 0,5 & 6 & 7 \\
IPSS Concelho de Matosinhos & 9 & 42,9 & 11 & 57,1 & 6,52 & 0,5 & 6 & 7 \\
IPSS Concelho de Caminha & 9 & 45,0 & 12 & 55,0 & 6,40 & 0,5 & 6 & 7 \\
\hline
\end{tabular}


O Rei (Carvalho, 2010). Esse instrumento avalia a precisão e fluência de leitura, através do registro do tempo despendido e dos erros cometidos pela criança na leitura do texto narrativo $\mathrm{O}$ Rei vai nu. $\mathrm{O}$ teste permite igualmente uma análise qualitativa dos erros cometidos pela criança durante a leitura. Neste estudo, essa prova apenas foi utilizada para avaliar a velocidade de leitura, calculada através do número de palavras lidas em um minuto.

Atividades de leitura e de escrita nas salas de jardim-de-infância. No sentido de caraterizar as atividades de leitura e de escrita realizadas no jardim-de-infância, foi construída um instrumento de Atividades de leitura e escrita no jardim-de-infância. Esse instrumento inclui um conjunto de afirmações sobre as práticas pedagógicas dos educadores no âmbito da linguagem oral e escrita. Os educadores indicam a frequência com que realizam as diferentes atividades, em uma escala tipo Likert de cinco pontos, que varia entre nunca e muitas vezes.

Atividades de Língua Portuguesa na sala de aula. A caracterização das atividades de Língua Portuguesa nas salas de aula do $1 .^{\circ}$ ciclo, bem como o modo de gestão da sala durante a realização de atividades de leitura e de escrita, foi realizada a partir de um instrumento de observação construído para o efeito e da Language Arts Activity Grid (LAAG; Cunningham, Zibulski, Stanovich, \& Stanovich., 2009). Assim, foram consideradas as principais atividades realizadas em torno da leitura e da escrita, de acordo com as sugestões de Cunningham e colaboradores (2009): (a) leitura orientada pelo professor; (b) escrita; (c) leitura autônoma; (d) discriminação de sons; (e) exploração da linguagem oral; (f) gramática e soletração; (g) compreensão leitora; (h) consciência fonêmica; (i) literatura; (j) reconhecimento automático de palavras; (k) correspondência letra-som e conceitos sobre o impresso; (1) vocabulário.

A gestão da sala de aula foi observada considerando as interrupções positivas (quando a interrupção se relacionava com o conteúdo que estava a ser abordado) e as interrupções negativas (quando a interrupção implicava a gestão de comportamentos disruptivos). Foi ainda registrado o tempo de transição entre tarefas e o tempo total alocado às diversas atividades.

\section{Procedimento}

Este estudo apresenta um design com três grupos e quatro medidas repetidas no tempo, relacionadas com a consciência fonológica (classificação com base na sílaba e fonema iniciais, e supressão com base na sílaba e fonema iniciais), com o reconhecimento de letras e com o reconhecimento de palavras. Nos dois últimos momentos de avaliação, foi introduzida uma nova variável associada à velocidade de leitura, representada pelo número de palavras lidas em um minuto. As avaliações foram realizadas ao longo do $1 .^{\circ} \mathrm{e} 2{ }^{\circ}$ anos de escolaridade, com início no ano letivo 2009/2010 e tendo terminado no ano letivo 2010/2011.

A avaliação das crianças foi efetuada nas instituições que frequentavam, após obtidas as autorizações dos respectivos Encarregados de Educação. Estes receberam esclarecimentos sobre os objetivos da investigação e foram informados da natureza das provas que seriam aplicadas.
A aplicação das provas com as crianças foi precedida de um esclarecimento junto às mesmas sobre as tarefas que iriam efetuar. A duração aproximada foi de 30 minutos por criança. A ordem de aplicação das provas foi mantida constante. As provas de reconhecimento de palavras e de velocidade de leitura foram apresentadas em formato de papel e as restantes, em formato digital.

A observação das salas de aula ocorreu durante o $2 .^{\circ}$ ano de escolaridade, sendo efetuadas duas observações em cada sala de aula e preenchido um instrumento de atividades de Língua Portuguesa por cada uma das professoras titulares de turma, que acompanharam as respetivas turmas durante os dois primeiros anos de escolaridade. Cada observação teve a duração aproximada de 50 minutos. Previamente foi explicitado aos docentes o objetivo da observação e acordado um momento específico para a sua realização.

No sentido de caraterizar as práticas pedagógicas dos educadores que pertenciam às três instituições de educação pré-escolar estudadas, foi utilizado um instrumento de Atividades de leitura e escrita no jardim-de-infância.

\section{Resultados}

Nas Tabelas 2, 3 e 4, são apresentados os resultados dos alunos ao longo dos dois primeiros anos de escolaridade. Esses resultados constituem o desempenho médio dos grupos de alunos provenientes dos três jardins-de-infância com práticas de literacia diferenciadas.

Em seguida, foram conduzidas análises de variância com duas ou com quatro medidas repetidas no tempo (conforme as variáveis utilizadas) e a consideração do fator grupo (ANOVAS`s mistas), com o objetivo de comparar as crianças provenientes dos três jardins-de-infância (cada um com um modelo educativo específico), no que tange ao processamento fonológico, bem como ao reconhecimento de letras, de palavras e da velocidade leitora, ao longo dos dois primeiros anos de escolaridade.

Os resultados da análise de variância, considerando quatro medidas repetidas no tempo e o fator grupo, são apresentados na Tabela 5 .

Relativamente à velocidade de leitura (medida através do número de palavras lidas por minuto) foram apenas realizadas duas medidas repetidas no tempo, a partir do $2 .^{\circ}$ ano de escolaridade. Os resultados da análise de variância mista sugerem que não ocorreram mudanças estatisticamente significativas em função do grupo de proveniência da educação pré-escolar entre esses dois momentos, na medida em que

Tabela 5. Análise de variância relativa ao desempenho dos alunos ao longo do tempo

\begin{tabular}{lcccc}
\hline & $\boldsymbol{F}$ & $\boldsymbol{g l}$ & $\boldsymbol{p}$ & $\boldsymbol{M .} \boldsymbol{E} \cdot$ \\
\hline Classificação Sílaba & 6,82 & 3,56 & 0,001 & 0,17 \\
Classificação Fonema & 9,08 & 4,11 & 0,001 & 0,21 \\
Supressão Sílaba & 5,06 & 3,50 & 0,01 & 0,13 \\
Supressão Fonema & 24,63 & 3,25 & 0,001 & 0,42 \\
Reconhecimento Letras & 46,45 & 2,06 & 0,001 & 0,58 \\
Reconhecimento Palavras & 13,98 & 5,11 & 0,001 & 0,29 \\
\hline Nota: gl-Graus de Liberdade; M.E.-Magnitude do Efeito
\end{tabular}

Nota: gl - Graus de Liberdade; M.E. - Magnitude do Efeito 
$F(2)=2,35, p>0,05$. Contudo, todos os grupos aumentam significativamente a velocidade de leitura do primeiro para o segundo momento de avaliação (cf. Tabela 6).

As professoras dos três grupos de alunos acompanhados ao longo dos dois primeiros anos de escolaridade referiram que utilizavam o método de ensino analítico-sintético e realizavam apenas duas atividades similares: orientação da leitura por parte do docente e exploração da gramática e da soletração. A docente do Jardim-Escola João de Deus mencionou que distribuía ainda o tempo entre atividades relacionadas com a leitura autônoma por parte dos alunos, a compreensão leitora, a linguagem oral e a escrita, sendo essa última atividade realizada durante menos tempo.

A docente responsável pelo grupo de alunos proveniente da IPSS de Matosinhos referiu que alocava as atividades de Língua Portuguesa à leitura autônoma por parte dos alunos, à linguagem oral, à consciência fonêmica e ao vocabulário. Verificou-se ainda que essa docente destinava um maior

Tabela 2. Estatística descritiva do desempenho dos alunos do Jardim-Escola João de Deus

\begin{tabular}{lcccccccc}
\hline & \multicolumn{7}{c}{ Jardim-escola João de Deus } \\
\cline { 2 - 10 } & \multicolumn{2}{c}{ M1 } & \multicolumn{7}{c}{ M2 } & \multicolumn{1}{c}{ M3 } & M4 & \\
\cline { 2 - 10 } & $M$ & $D P$ & $M P$ & $M$ & $D P$ & $M$ & $D P$ \\
\hline Sil.in & 11,83 & 2,99 & 12,79 & 2,18 & 13,55 & 1,53 & 13,87 & 0,35 \\
Fon.in & 11,10 & 3,60 & 12,31 & 2,58 & 13,45 & 1,94 & 13,97 & 0,18 \\
Sup.sil & 12,07 & 2,31 & 13,62 & 1,01 & 13,52 & 2,52 & 14 & 0,00 \\
Sup.fon & 20,55 & 5,85 & 23,62 & 1,01 & 23,87 & 0,44 & 23,62 & 1,86 \\
Letras & 22,90 & 0,31 & 22,90 & 0,40 & 22,97 & 0,18 & 23,00 & 0,18 \\
PRP & 24,83 & 5,78 & 30,87 & 7,33 & 35,76 & 4,96 & 38,76 & 1,59 \\
REI & & & & & 226,69 & 56,77 & 254,97 & 36,35 \\
\hline
\end{tabular}

Nota: Sil.in - Sílaba inicial; Fon.in - Fonema inicial; Sup.sil - Supressão de sílaba; Sup.fon. - Supressão de fonema

Tabela 3. Estatística descritiva do desempenho dos alunos do jardim-de-infância da IPSS do Concelho de Matosinhos

\begin{tabular}{lcccccccc}
\hline & \multicolumn{8}{c}{ IPSS Concelho Matosinhos } \\
\cline { 2 - 10 } & \multicolumn{7}{c}{ M1 } & \multicolumn{7}{c}{ M2 } & \multicolumn{1}{c}{ M3 } & M4 & \\
\cline { 2 - 9 } & $M$ & $D P$ & $M$ & $D P$ & $M$ & $D P$ & $M$ & $D P$ \\
\hline Sil.in & 9,05 & 3,61 & 12,09 & 2,50 & 12,90 & 2,66 & 13,43 & 1,43 \\
Fon.in & 7,48 & 4,07 & 10,81 & 3,58 & 12,29 & 2,92 & 13,77 & 0,54 \\
Sup.sil & 11,95 & 2,66 & 13,29 & 1,42 & 13,86 & 0,65 & 13,95 & 0,21 \\
Sup.fon & 9,19 & 8,43 & 22,48 & 3,42 & 23,95 & 0,22 & 23,90 & 0,44 \\
Letras & 18,90 & 4,40 & 22,95 & 0,22 & 23,00 & 0,00 & 23,0 & 0,00 \\
PRP & 8,00 & 5,00 & 22,29 & 6,33 & 31,76 & 5,60 & 35,09 & 5,25 \\
REI & & & & & 176,10 & 59,43 & 221,33 & 55,14 \\
\hline
\end{tabular}

Nota: Sil.in - Sílaba inicial; Fon.in - Fonema inicial; Sup.sil - Supressão de sílaba; Sup.fon. - Supressão de fonema

Tabela 4. Estatística descritiva do desempenho dos alunos do jardim-de-infância do Concelho de Caminha

\begin{tabular}{lcccccccc}
\hline & \multicolumn{8}{c}{ Ipss Concelho Caminha } \\
\cline { 2 - 10 } & \multicolumn{2}{c}{ M1 } & \multicolumn{1}{c}{ M2 } & \multicolumn{2}{c}{ M3 } & M4 & \\
\cline { 2 - 10 } & $M$ & $D P$ & $M$ & $D P$ & $M$ & $D P$ & $M$ & $D P$ \\
\hline Sil.in & 7,25 & 4,72 & 11,90 & 3,19 & 13,60 & 1,57 & 13,25 & 2,68 \\
Fon.in & 4,85 & 3,86 & 10,25 & 3,45 & 13,05 & 2,35 & 13,35 & 2,68 \\
Sup.sil & 8,65 & 4,63 & 12,45 & 2,82 & 13,65 & 1,35 & 13,40 & 2,68 \\
Sup.fon & 4,70 & 4,75 & 19,20 & 7,52 & 22,70 & 4,30 & 22,85 & 5,14 \\
Letras & 12,50 & 5,25 & 22,70 & 0,57 & 23,00 & 0,00 & 22,95 & 0,22 \\
PRP & 5,75 & 7,85 & 17,95 & 8,57 & 26 & 9,12 & 29,25 & 8,94 \\
REI & & & & & 129,25 & 71,86 & 177,05 & 69,66 \\
\hline
\end{tabular}

Nota: Sil.in - Sílaba inicial; Fon.in - Fonema inicial; Sup.sil - Supressão de sílaba; Sup.fon. - Supressão de fonema 
Tabela 6. Desempenho dos alunos no último momento de avaliação

\begin{tabular}{|c|c|c|c|c|c|c|c|c|c|c|c|c|}
\hline & \multirow[b]{2}{*}{ Min. } & \multirow[b]{2}{*}{ Máx. } & \multicolumn{2}{|c|}{ JE João Deus } & \multicolumn{2}{|c|}{$\begin{array}{c}\text { IPSS } \\
\text { Matosinhos }\end{array}$} & \multicolumn{2}{|c|}{$\begin{array}{c}\text { IPSS } \\
\text { Caminha } \\
\end{array}$} & \multirow[t]{2}{*}{$F$} & \multirow[t]{2}{*}{$\boldsymbol{G l}$} & \multirow[t]{2}{*}{$p$} & \multirow[t]{2}{*}{ M. E. } \\
\hline & & & $M$ & $D P$ & $M$ & $D P$ & $M$ & $D P$ & & & & \\
\hline Classificação Sílaba & 0 & 14 & 13,87 & 0,35 & 13,43 & 1,43 & 13,25 & 2,68 & 0,71 & 2 & n.s. & - \\
\hline Classificação Fonema & 0 & 14 & 13,97 & 0,18 & 13,77 & 0,54 & 13,35 & 2,68 & 1,06 & 2 & n.s. & - \\
\hline Supressão Sílaba & 0 & 14 & 14 & 0,00 & 13,95 & 0,21 & 13,40 & 2,68 & 1,18 & 2 & n.s. & - \\
\hline Supressão Fonema & 0 & 24 & 23,62 & 1,86 & 23,90 & 0,44 & 22,85 & 5,14 & 0,68 & 2 & n.s. & - \\
\hline Reconhecimento Letras & 0 & 23 & 23,00 & 0,18 & 23,0 & 0,00 & 22,95 & 0,22 & 1,26 & 2 & n.s. & - \\
\hline Reconhecimento Palavras & 0 & 40 & 38,76 & 1,59 & 35,09 & 5,25 & 29,25 & 8,94 & 16,74 & 2 & 0,001 & 0,33 \\
\hline Número palavras minuto & 0 & 281 & 100,49 & 28,82 & 81,30 & 29,53 & 60,45 & 26,42 & 11,86 & 2 & 0,001 & 0,26 \\
\hline
\end{tabular}

Nota: gl - Graus de Liberdade; M.E. - Magnitude do Efeito

Tabela 7. Sistematização das observações efectuadas na sala de aula

\section{Organização de conteúdos no}

âmbito da leitura e da escrita

Jardim-escola João de Deus

EB1 (IPSS) Concelho de Matosinhos

EB1 (IPSS) Concelho de Caminha

\section{Leitura silenciosa e individual \\ do texto; compreensão oral do texto; pesquisa no dicionário de palavras desconhecidas e de sinónimos; audição de uma história; resumo escrito colectivo.}

Leitura oral individual do texto; compreensão oral; tarefas de consciência fonológica; identificação de palavras novas.

Leitura individual do texto de modo silencioso e oral; leitura do texto por parte da professora; realização de exercícios de compreensão; realização de exercícios de consciência fonológica

\section{Interrupções/ Transições}

Existência de muitas

interrupções positivas

relacionadas com comentários

dos alunos sobre os conteúdos

abordados.

Existência de algumas

interrupções negativas

relacionadas com a gestão de

comportamentos disruptivos.

Existência de algumas

interrupções negativas

relacionados com a gestão de

comportamentos disruptivos.

\section{Tempo alocado à tarefa}

$85 \%$ do tempo total da observação foi dedicado à instrução da leitura e da escrita.
$72 \%$ do tempo total da observação foi dedicado à instrução da leitura e da escrita.

$70 \%$ do tempo total da observação foi dedicado à instrução da leitura e da escrita. período de tempo a atividades relacionadas com as letras, os sons e os conceitos sobre o impresso.

A docente responsável pelo grupo de alunos proveniente da IPSS de Caminha mencionou que, para além das atividades similares às das demais docentes, realizava atividades de escrita e de linguagem oral.

Por meio da observação efetuada no contexto da sala de aula, foi possível analisar a intencionalidade e a produtividade das atividades realizadas no âmbito da língua portuguesa, bem como os momentos de interrupção e transição entre tarefas (cf. Tabela 7).

\section{Discussão}

Este estudo procurou analisar as implicações, na aprendizagem formal da leitura, de tipos diferenciados de abordagem à leitura e à escrita no jardim-de-infância, ao longo dos dois primeiros anos de escolaridade. A análise do desempenho na leitura ao longo dos dois primeiros anos de escolaridade, em função do grupo de proveniência da educação pré-escolar, permite constatar que ocorrem mudanças significativas nos desempenhos dos alunos nos quatro momentos de avaliação e que o grupo de alunos provenientes do Jardim-Escola João de Deus (onde há aprendizagem formal da leitura) apresenta melhores desempenhos do que os demais grupos de alunos nos quatro momentos. $\mathrm{O}$ desempenho dos alunos provenientes das IPSSs dos concelhos de Caminha (sem qualquer prática específica de literacia) e de Matosinhos (treino sistemático de competências fonológicas) é similar e evolui de forma idêntica ao longo dos quatro momentos de avaliação.

As diferenças entre os três grupos atenuam-se ao longo do tempo nas provas relacionadas com o processamento fonológico e com o reconhecimento de letras. Esses resultados apontam para um efeito da instrução direta da leitura/ escrita, com equalização paulatina dos desempenhos nessas áreas. Isso sugere que, embora as experiências precoces com a leitura e a escrita durante a educação pré-escolar sejam importantes para desenvolver competências e atitudes sobre a linguagem escrita, podendo facilitar a aquisição da decodificação leitora (Martins \& Farinha, 2006; Yopp \& Stapleton, 2008), a instrução formal e direta da leitura poderá 
ser o verdadeiro motor para o desenvolvimento não só do reconhecimento de letras (o que é óbvio) mas também do conhecimento fonológico (o que é menos óbvio) (Perfetti, Beck, Bell, \& Hugues, 1987; Silva, 2003; Wagner e Torgesen, 1994; Velasquez, 2007). Parece, assim, verificar-se uma relação bidirecional entre as competências de processamento fonológico e o reconhecimento de palavras, em que as primeiras facilitam o desenvolvimento do segundo e em que o reconhecimento de palavras, aprendido através da instrução formal e da prática, promove as competências fonológicas (Bast \& Reitsma, 1998).

Note-se, porém, que, apesar de atenuadas, as diferenças de velocidade de leitura no final do $2 .^{\circ}$ ano se mantêm, o que poderia, de alguma forma, sustentar a hipótese de influência das experiências pré-escolares nesse domínio. Infelizmente essa interpretação se depara com a dificuldade metodológica de separar eventuais efeitos do modelo educativo pré-escolar dos efeitos da instrução formal no $1 .^{\circ} \mathrm{e} 2 .^{\circ}$ ano de escolaridade. No entanto, é possível constatar que os professores dos três grupos estudados tendem a alocar tempo idêntico a um conjunto de tarefas similares relacionadas com a instrução explícita da leitura. As atividades privilegiadas relacionam-se com a orientação da leitura por parte do docente, a exploração da gramática e da soletração, a leitura autônoma, a promoção da compreensão leitora e da linguagem oral e o treino da escrita (Cunningham et al., 2009).

Analisando os aspectos diferenciadores das práticas dos três docentes, verifica-se que o professor do grupo proveniente da IPSS de Matosinhos é o único que realiza uma tarefa distinta dos demais professores, relacionada com a articulação entre as letras, os sons e os conceitos sobre o impresso, sendo ainda aquele que lhes dedica mais tempo. Um outro elemento diferenciador das práticas dos docentes relaciona-se com o modo como é realizada a gestão da sala de aula. Enquanto o professor do Jardim-Escola João de Deus despendia menos tempo em interrupções, alocando praticamente todo o tempo da aula a atividades relacionadas com a leitura e a escrita, os demais docentes despendiam grande parte do tempo a gerir interrupções relativas a problemas de comportamento. Uma possível explicação para essa situação pode relacionar-se com o fato de os comportamentos disruptivos dos alunos surgirem quando estes percebem que não conseguem acompanhar o currículo escolar, prejudicando a concretização de atividades de instrução (Lopes, 2003).

O modo de gestão da sala e o tipo de atividades realizadas no âmbito da leitura e da escrita no Jardim-escola João de Deus parecem fomentar não só competências nesse domínio, mas também parecem promover competências de autorregulação da aprendizagem. O professor intervém apenas quando necessário e prepara os alunos para desafios mais complexos. Os alunos aprendem a gerir a sua motivação e os seus comportamentos mesmo quando os textos e as palavras são desconhecidos (Perrenoud, 1999).

Ainda que com a ressalva enunciada, o desempenho superior dos alunos do Jardim-Escola João de Deus no final do $2 .^{\circ}$ ano pode dever-se a duas situações distintas. Por um lado, a instrução direta aos cinco anos permite que os alunos se tornem mais cedo leitores automáticos, apresentando, por consequência, melhores resultados na fluência de leitura, os quais poderão ou não manter-se no futuro. Por outro lado, a competência leitora desses alunos pode relacionar-se apenas com o tipo de ensino específico da leitura que ocorre nessa instituição no $1 .^{\circ}$ ciclo e que, no caso particular das Escolas João de Deus, obedece ao mesmo modelo entre os 5 e os 9 anos de idade (pré-escolaridade e $1 .^{\circ}$ ciclo).

A comparação dos nossos resultados com os do estudo realizado por Scanlon e Vellutino (1997), no qual os autores procuraram avaliar o impacto das práticas de três jardins-de-infância no sucesso na aprendizagem da leitura no $1 .^{\circ}$ ciclo, sugere que a principal distinção nas práticas de jardim-de-infância reside no modo formal (instrução direta) /informal (trabalho sistemático e deliberado de promoção de literacia emergente) como são realizadas as tarefas de abordagem à leitura e à escrita. Note-se porém que Scanlon e Vellutino verificaram que alguns alunos que obtêm sucesso na aprendizagem formal da leitura apresentam, à entrada do $1 .^{\circ}$ ano de escolaridade, reduzidos desempenhos ao nível da literacia emergente, o que significa que é a instrução direta nas correspondências grafemas-fonemas que permite às crianças aceder à leitura e não tanto o nível de literacia emergente. Aliás, diversas investigações têm vindo a demonstrar que existem influências recíprocas entre algumas competências de literacia emergente desenvolvidas antes do ingresso na escolaridade obrigatória e a aprendizagem formal da leitura (Cadime et al., 2009; Martins \& Niza, 1998; Silva, 2003).

De modo geral, o nosso estudo permitiu refletir sobre a importância das experiências precoces de confronto com a linguagem escrita e da instrução explícita da leitura. Os resultados encontrados sugerem que o modo como as crianças iniciam o $1 .^{\circ}$ ano de escolaridade condiciona moderadamente a aprendizagem formal da leitura. Contudo, esse efeito só é aparente quando existe um modelo muito distinto e em que se faz intencionalmente no jardim-de-infância o mesmo que no $1 .^{\circ}$ ciclo, ou seja, instrução direta da leitura/escrita.

\section{Conclusão e Limitações}

O presente estudo revela que as experiências vividas pelas crianças provenientes das três instituições estudadas, designadamente, as oportunidades, quantidade e variedade de leitura e de exploração da linguagem escrita, são distintas conforme o modelo educativo adotado pelo educador e/ou instituição que as crianças frequentam. Os resultados encontrados sugerem que o ensino formal que ocorre no Jardim-Escola João de Deus permite que os alunos que provêm dessa instituição apresentem melhores desempenhos na decodificação e fluência leitora em comparação com os demais alunos no primeiro ano de escolaridade, o que era evidentemente esperado, uma vez que têm já um ano de experiência nessa área. Os resultados evidenciam, porém, duas situações menos óbvias: os alunos João de Deus (a) revelam uma superioridade muito grande nas provas fonológicas, mesmo em relação ao grupo de alunos que recebeu instrução específica nesta área e (b) mantêm superioridade na velocidade de leitura no final do $2 .^{\circ}$ ano, ainda que de forma menos evidente. Quanto a esse 
último ponto, seria importante que avaliações posteriores desses grupos de alunos permitissem perceber se as diferenças se mantêm ou se a tendência para a aproximação dos grupos se acentua. Será igualmente importante comparar os desempenhos dos alunos do Jardim-Escola João de Deus aos 5 anos de idade com alunos do $1 .^{\circ}$ ano de escolaridade de outras instituições de ensino em que a instrução direta apenas se inicia aos 6 anos.

O primeiro ponto é ainda mais relevante do que o segundo, porque sugere que a forma mais eficaz de promover o conhecimento fonológico é ensinar diretamente a leitura (i.e. as correspondências grafo-fonológicas). Este resultado, devido às suas implicações práticas, deverá ser explorado de forma mais sistemática em estudos futuros no sentido de perceber em que circunstâncias é que tal se verifica.

Relativamente às limitações deste estudo deve assinalar-se fundamentalmente a dificuldade em controlar alguns fatores, em particular a instrução, a qual constitui uma das variáveis que mais condiciona o percurso escolar dos alunos, e cujo controle se procurou assegurar através da descrição das práticas dos docentes envolvidos no estudo. Ainda assim, há a possibilidade de as diferenças entre os grupos refletirem tanto ou mais as diferenças do ensino na escolaridade formal do que as diferenças no jardim-de-infância. Esses aspectos deverão ser contemplados em futuras investigações, procurando traçar as respetivas trajetórias escolares dos alunos, bem como verificar se os desempenhos ao nível da decodificação e fluência leitora condicionam a compreensão leitora.

\section{Referências}

Bast, J., \& Reitsma, P. (1998). Analyzing the development of individual differences in terms of Mathew effects in reading: Results from a Dutch longitudinal study. Development Psychology, 34(6), 1373-1399.

Cadime, I., Fernandes, I., Brandão, S., Nóvoa, P., Rodrigues, A., \& Ferreira, A. (2009). A aquisição da leitura e da escrita: variáveis preditoras no nível pré-escolar. Actas do X Congresso Internacional Galego-Português de Psicopedagogia (pp. 40014015). Braga: Universidade do Minho.

Carvalho, A. (2010). O Rei - Teste de Fluência e Precisão da Leitura. Vila Nova de Gaia: EDIPSICO.

Castro, S. L., \& Gomes, I. (2000). Dificuldades de aprendizagem da lingua materna. Lisboa: Universidade Aberta.

Cruz, J. (2011). Práticas de literacia familiar e o desenvolvimento literácito das crianças (Tese de Doutoramento não-publicada). Braga: Universidade do Minho.

Cunningham, A. E., Zibulski, J., Stanovich, K. E., \& Stanovich, P. J. (2009). How teachers would spend their time teaching language arts: The mismatch between self-reported and best practices. Journal of Learning Disabilities, 42(5), 418-430.

Fernandes, P. P. (2005). Concepções e práticas de literacia emergente em contexto de jardim-de-infância (Tese de Doutoramento não-publicada). Braga: Universidade do Minho.

Kendeou, P., Broek,P., White, M. \& Lynch, J. (2009). Predicting reading comprehension in early elementary school: The independent contributions of oral language and decoding skills. Journal of Education Psychology, 101(4), 765-778.
Koutsoftas, A. D., Harmon, M. T., \& Gray, S. (2009). The effect of Tier 2 intervention for phonemic awareness in a responseto-intervention model in low-income preschool classrooms. Language, Speech, and Hearing Services in Schools 40(2), 116-130. doi: 10.1044/0161-1461(2008/07-0101)

Lima, R. (2009). Fonologia infantil: Aquisição, avaliação e intervenção. Coimbra: Edições Almedina.

Lopes, J. (2003). Problemas de comportamento, problemas de aprendizagem, problemas de "ensinagem”. Coimbra: Quarteto Editora.

Lopes, J. (2010). Conceptualização, avaliação e intervenção nas dificuldades de aprendizagens: A sofisticada arquitectura de um equívoco. Braga: Psiquilíbrios Edições.

Lopes, J., \& Fernandes, P. P. (2009). Emergent literacy beliefs in preschool and kindergarten contexts. L1 - Educational Studies in Languages and Literature, 9(4), 5-26.

Martins, M. A., \& Niza, I. (1998). Psicologia da aprendizagem da linguagem escrita. Lisboa: Universidade Aberta.

Martins, M. A., \& Silva, C. (2006). Phonological abilities and writing among Portuguese preschool children. European Journal of Psychology of Education, 21(2), 163-182.

Martins, M., \& Farinha, S. (2006). Relação entre os conhecimentos iniciais sobre linguagem escrita e os resultados em leitura no final do $1^{\circ}$ ano de escolaridade. Livro de Actas da XI Conferência Internacional de Avaliação Psicológica: Formas e Contextos (pp. 1051-1060). Braga: Psiquilíbrios Edições.

McGuinness, D. (2005). Language development and learning to read. The scientific study of how language development affects reading skill. Massachusetts: The MIT Press.

Ministério da Educação. (1997). Orientações Curriculares para o Ensino Pré-Escolar. Lisboa: D.E.B. - Núcleo de Ensino Pré-Escolar.

Perfetti, C. A., Beck, I., Bell, L., \& Hugues, C. (1987). Phonemic knowledge and learning to read are reciprocal: A longitudinal study of first grade children. Merrilpalmer Quarterly, 33, 283-319.

Perrenoud, P. (1999). Avaliação: Da excelência à regulação das aprendizagens - Entre duas lógicas. Porto Alegre: Artes Médicas Sul.

Ruivo, I. (2006). João de Deus: Método de leitura com sentido. Actas do VI encontro nacional (IV internacional) de investigação em leitura, literatura infantil e ilustração (pp. 1-14). Braga. Universidade do Minho.

Scanlon, D., \& Vellutino, F. (1997). A comparison of the instructional backgrounds and cogitive profiles of poor, average, and good readers who were initially identified as at risk for reading failure. Scientific Studies of Reading, 1(3), 191-215.

Silva, A. C. (2002). Bateria de Provas Fonológicas. Lisboa, Edições ISPA.

Silva, A. C. (2003). Até à descoberta do princípio alfabético. Lisboa: Fundação Calouste Gulbenkian.

Sim-Sim, I. (1998). Desenvolvimento da linguagem. Lisboa: Universidade Aberta.

Sim-Sim, I. (2001). A formação para o ensino da leitura. Cadernos de Formação de Professores, 2, 51-64.

Spear-Swerling, L., \& Sternberg, R. J. (1996). Off track: When poor readers become "learning disabled". Oxford: Westview Press. 
Velasquez, M. G. (2007). Percursos desenvolvimentais de leitura e escrita: Estudo longitudinal com alunos do $1 .^{\circ}$ ciclo do ensino básico (Tese de Doutoramento não-publicada). Braga: Universidade do Minho.

Vellutino, R. F., \& Scanlon, D. M. (1987). Phonological coding, phonological awareness and reading ability: Evidence from a longitudinal and experimental study. Merril-Palmer Quarterly, 33(3), 321-363.
Viana, F., \& Ribeiro, I. (2006). PRP: Prova de reconhecimento de palavras. Lisboa: CEGOC-TEA.

Wagner, R. K., Torgesen, J. K., \& Rashotte, C.A. (1994). Development of reading-related phonological processing abilities: New evidence of bidirectional causality from a latent longitudinal study. Developmental Psychology, 30, 73-87.

Yopp, H., \& Stapleton, L. (2008). Conciencia fonémica en Español. The Reading Teacher, 61(5), 374-382.

Recebido em 13.05.2014

Primeira decisão editorial em 12.11.2014

Versão final em 12.11.2014

Aceito em 05.05.2015 